\title{
The Effect of Transparency Policies on Shadow Economy: Measurement and Evidence from Korea
}

\author{
Ki Beom Binh ${ }^{\mathrm{a}}$, Myung-Ho Park ${ }^{\mathrm{b}}$ and Seokjin Woo ${ }^{\mathrm{a},}$ \\ ${ }^{a}$ Department of Economics, Myongji University, South Korea \\ ${ }^{b}$ School of Economics, Hongik University, South Korea
}

\begin{abstract}
This paper provides a new and simple methodology to examine the relative size of the shadow economy to the official one using the quantity theory of money identity. We measure the shadow economy size in Korea annually. The Korean government has implemented various transparency policy measures to identify the tax source in commercial transactions. We find significant evidence that credit card encouragement and the cash payment receipt system have a negative effect on the shadow economy size.
\end{abstract}

Keywords: Shadow economy, transparency policy, credit card, cash payment receipt, quantity theory of money identity.

\section{INTRODUCTION}

The economic loss that the shadow economy (often called as underground economy, black economy, unofficial economy, informal sector, hidden economy or subterranean economy) brings about is well known in the related literatures (Feige, 1989; Thomas, 1999; Fleming, Roman, and Farrell, 2000; Tanzi 1983, 1986; Schneider, 2005, 2018; Schneider, Buehn, and Montenegro, 2010). Most governments have pursued policy measures to uncover the shadow economy. The Korean government is not an exception. The country has made considerable efforts to reduce the size of the informal sector and implemented diverse policies which could improve the transparency in commercial transactions of the Korean economy.

The transparency policies of Korea range from encouraging double-entry bookkeeping for selfemployed small businesses and the usage of credit cards for consumers to the introduction of cash payment receipt (CPR, hereafter). The unique feature lies in the tax treatment of the transactions with credit cards and the CPR. Some amounts for credit card usage and cash payment receipts with pre-determined caps were allowed to be deductible from the taxable income in personal income tax. The tax treatments provided pecuniary incentives for consumers to use credit card more often and require the sellers to issue the CPR. As a result, the National Tax Service (NTS, hereafter) of Korea became able to make commercial transactions more transparent at the cost of tax

*Address correspondence to this author at the Department of Economics, Myongji University, South Korea; Tel: +82-2-300-0688; Fax: +82-2-300-0654; E-mail: genoswoo@gmail.com

JEL Classification: $\mathrm{H} 25, \mathrm{H} 26$, E26. expenditure. In 2012, the amounts of transactions settled by credit cards and CPR were approximately KRW 485 trillion and KRW 62 trillion, respectively.

Contrarily, BOK (Bank of Korea), the central bank in Korea, has issued a high-denomination currency, i.e., the KRW 50,000 bill since 2009 , the issuance size of which amounted to 32 trillion KRW at the end of 2012. However, the outstanding circulation of it shrinks gradually even now. We can expect that the KRW 50,000 bills would be used as transaction means or stores of value in the underground economy.

There has been no consensus among previous studies on either the size or trend of the shadow economy of Korea. Korean scholars report that the size of the economy ranges from 10 percent (Choi, 1987) through 42 percent (Kim et al., 2008). It depends on the periods under investigation, the determinants, and mostly the estimation model (Moon and Park, 1999, 2002). Regarding the trend, there is no consensus either. For example, Park (2009) reports that the share of the recent shadow economy in the total GDP decreased from $26.4 \%$ in 2006 to $15.8 \%$ in 2008 using the tax report data. In contrast, Sung (2008) shows that the shadow economy is still increasing, based upon the difference between the actual per capita tax from NTS and the estimated per capita tax which should be levied under the Household Income Survey. Kim et al. (2008) suggests mixed results that the size of the shadow economy of Korea fluctuates significantly despite the declining trend. On the other hand, Schneider et al. (2010) claims that the size of the Korean shadow economy is still fairly high and increased from $27.5 \%$ in 1996 to $29.2 \%$ in 2007. Meanwhile, the so-called DYMIMIC method based on the state-space model approach has been developed by Tedds and Giles 
(2002), Bajada and Schneider (2005), Schneider (2005, 2018), Schneider et al. (2010), and Schneider and Enste (2002), among others. However, the counterarguments against the DYMIMIC (dynamic multiple-indicator multiple-cause) method have persuasive econometric rationales. (Helberger and Knepel, 1988; Smith, 2002; Hill, 2002; Breusch, 2005).

This study aims to examine the effect of Korea's transparency policies on the size of its shadow economy. In particular, we focus on the role of the credit card and CPR-based transparency policy of Korea. Our approach is different from previous studies in the following two aspects. First, we explicitly included the government effort to reduce the shadow economy, which is an important factor to determine the size of the shadow economy, but has been ignored in the existing literatures. We believe that Korea's transparency policy using tax reduction tool constitutes a unique and relevant policy variation to identify the policy effect. Second, we developed a new and simple model for estimating the size of the shadow economy. The model that we propose constitutes the quantity theory of money identity $M \cdot v=P \cdot y$ of shadow and official sectors as well as the total economy. However, our approach differs from the previous money demand function methods of Tanzi $(1983,1986)$ who is the researcher triggering the issue of underground economy measurement from Cagan's (1958) perspective and the so-called transaction method by Feige (1979).

\section{INSTITUTIONAL BACKGROUNDS FOR TRANSPARENCY POLICIES IN KOREA}

From 1999, the NTS (Korean National Tax Service), Korean tax authority, has allowed income deduction on a certain amount of expenditure paid by credit cards, debit cards, which have often been called as check card in Korea, and cash with cash-payment receipts to the individual income tax filers. For example, in 1999, the expenditure by credit card constituting over 10 percent of the total income could be deductible from the taxable income at 10 percent rate. The maximum amount is the smaller one of KRW 3 million or 20 percent of the total income for a household. The deduction rates were $15 \%$ for credit card and $30 \%$ for debit card, respectively, at the end of 2013. This tax incentive encouraged consumers to use credit cards or debit cards more frequently even with small transactions. Consecutively, the commercial transactions were reported to the NTS through the electronic network automatically and became more transparent. In most markets in Korea, consumers can use either credit card or debit card and ask for issuance of receipt in transactions.

In order to provide incentives to sellers, the Korean government allowed them to claim tax credit from value-added tax for the amount of total sales which was paid for by credit cards at a rate of 1.0 percent. The maximum amount was KRW 3 million in 1999, which increased up to KRW 7 million in 2009.

Similar to other developing countries, the preference for cash payment and settlement has been prevalent in Korea. The transactions based on cash payment are a potential source of the shadow economy. Unless the consumer receives cash receipt for a cash trade (spot trade), no one, including the NTS, recognizes the transaction.

In order to bring the cash transactions to light, the NTS introduced the so-called "Cash Payment Receipt (CPR)" system in 2005. Under the CPR system, the consumers can require the sellers an issuance of the receipt for the spot purchase paid by cash and the volume of the trade is electronically reported to the NTS. Sellers have legal obligations to issue the CPR on consumer's request. If a seller declines it and such denial can be reported to the NTS by the customer, the former can face steep fine and a percentage of the fine (usually 10 percent) is returned to the customer as a reward. The accumulated volume of the CPR is allowed to be deductible from taxable income as summed with credit card and debit card usage. Moreover, the NTS of the government has allowed the deduction rate of $30 \%$ for the expenditure by CPR above $10 \%$ of the total income.

\section{MODEL AND ESTIMATION}

\section{A. Quantity Theory of Money Identity Method}

In Tanzi's approach $(1983,1986)$, the currency (or money) demand without considering the informal economy is obtained by assuming a zero tax rate after estimating the currency demand as a function of the tax rate. The difference between the actual currency demand and the counterfactual one with zero tax rate is regarded as the currency circulated in the shadow economy. In this model, the tax burden imposed by the government works as a unique factor of the shadow economy.

However, Tanzi's identification strategy depends upon an arbitrary assumption that the size of the 
shadow economy is an increasing function of the tax rate. If the estimated coefficient of the tax rate is negative, the model is hardly interpretable.

The main idea of our model is similar to that of Tanzi's approach in that we take advantage of the size of currency circulated in the economy. Cagan (1958) argued that the degree of tax evasion determines currency demand. Porter and Weinbach (1999) and Pickhardt and Pons (2006) also estimated the shadow economy using the currency ratio. Our method, however, differs from Tanzi's model in that we attempted to avoid arbitrary assumptions and be explicit about identification conditions.

Consider two sectors in the economy: official sector and unofficial sector. Our model is basically based upon the quantity theory of money identity. Specifically, in order to estimate the size of the shadow economy relative to GDP, we investigated the following three money quantity identities for the official, shadow, and total economy:

$$
\begin{aligned}
& M^{G} \times v^{G}=P \times G \\
& M^{H} \times v^{H}=P \times H \\
& M \times v=P \times T .
\end{aligned}
$$

Equations (1), (2), and (3) represent the money quantity identity for the official, shadow, and total economy, respectively. $P$ is the price level of the official economy. $G$ is the real GDP. So the right-hand side of Equation (1), $P \times G$, is the nominal trade volume in the official sector. $H$ in Equation (2) reflects the real output in the shadow economy by deflating through the official economy price $P$. Thus, the right-hand side of equation (2) is the nominal output evaluated by the price level of the official economy. We should note that the two sectors are not separable but connected with each other since an economic agent trades in both official and unofficial sectors. So the two sectors are entangled with each other as if Möbius strip. Moreover, there is a price level $P_{H}$ in the unofficials different from the $P$. Then the size of the unfficials would be $P_{H} \cdot H^{\prime}$. Since $P \cdot \frac{P_{H} \cdot H^{\prime}}{P}$, we can set $\frac{P_{H} \cdot H^{\prime}}{P}=H$. So the equation (2) does not lose a generality. $M^{G}$ and $M^{H}$ represent the $M 1$ circulating in each sector. $v^{G}$ and $v^{H}$ represent the corresponding money velocities in each sector. In Korea, M1 is narrow money defined as the sum of currency and transferable deposits including bank demand deposits, bank saving deposits, MMDA (money market deposit account) and MMF (money market fund).
The last equation, Equation (3) is the money quantity identity for the total economy, including both official and unofficial sectors. $M$ represents $M 1$ and denotes the total money supplied for payment and settlement for every kind of commercial transactions and $v$ is the corresponding velocity.

Note that only $P, G$, and $M$ are known. It is impossible to derive the size of the shadow economy relative to (official) GDP, $H / G$, without further assumptions. With $M 1=C+D$, where $C$ is the currency and $D$ is the transferable deposits, we can rewrite equations ( 1 ) and (2) as follows:

$$
\begin{aligned}
& {[(1-p) C+q D] v^{G}=P \cdot G} \\
& {[p C+(1-q) D] v^{H}=P \cdot H,}
\end{aligned}
$$

where $p$ is a portion of the currency $C$ circulated in the unofficial sector, and similarly, $q$ is the portion of transferable deposits $D$ circulated in the official sector. In other words, some portion of cash, $p$, in the economy is used to support the transactions in the unofficial sector and some portion, $q$, of transferable deposits is used in the official economy.

One extreme case is that both $p=1$ and $q=1$. That is, the cash is used only in the unofficial sector, while the transferable deposits are used only in the official sector. Even in this case, it is still impossible to pin down $H$ because $V^{H}$ is not known yet. On the other hand, it should be recognized that the Korean won $\mathrm{KRW}$ is not used in the international currency but only in Korea. It is domestic and local currency and has been regulated not to be circulated in abroad by Korean law, Act of Foreign Exchage Trade. Cebula (2014) argues that the US dollar circulated abroad outside U.S. would be related to the U.S. underground economy.

Note that the money velocity of the total economy is the weighted average of $v^{H}$ and $v^{G}$ as follows:

$v=\frac{M^{G}}{M} v^{G}+\frac{M^{H}}{M} v^{H}$.

It is reasonable to assume that the money supply in the official economy is by far larger than that in the shadow economy. Based on this prior assumption, we further assume that the money velocity of the total economy is a point between $v^{H}$ and $v^{G}$, i.e., $v^{H}<v<v^{G}$.

On the other hand, to compute the size of the shadow economy size, we can derive Equation (7). 
$\frac{H}{G}=\frac{P H}{P G}=\frac{M v-P G}{P G}=\frac{M v}{P G}-1$

Since $M \cdot v$ is equal to the total GDP in both sectors and total GDP is greater than the official GDP, the ratio $\frac{H}{G}$ would be larger than 0 in equation (7). We observe that if all currency and deposit in $M 1$ are used only in the official economy, i.e., $M 1=M 1^{G}$, then the ratio $\frac{H}{G}$ could be zero. Moreover, the parameter $P$ representing the price index in the official economy would be redundant in estimating the relative size of the shadow economy.

Let us narrow the range of the velocity $v$. Noting that $\frac{M^{G}}{M} v^{G}<v<v^{G}$ owing to Equation (6), we take $v$ as the midpoint of the interval, i.e., $v=\frac{M^{G}+M}{2 M} v^{G}$.. Then, the relative ratio of the shadow economy can be estimated as follows:

$\frac{\hat{H}}{G}=\frac{M}{P G} \cdot \frac{M^{G}+M}{2 M} v^{G}-1=\frac{M^{G}+M}{2 P G} v^{G}-1$.

To apply this procedure, the values of both $p$ and $q$ in equations (4) and (5) must be determined. However, information on the parameters is never known yet. We have to take advantage of our subjective prior assumptions to determine the values of the parameters. In the modern economy with financial innovations due to ICT, and well accepted payment and settlement instruments such as checks and credit and check cards, we rarely need to hold and use cash. Moreover, the Korean government allows income deduction for transactions made by credit/debit card or cash with cash-payment receipt, as mentioned earlier. Thus, although the transactions accompanying CPR happen in the official economy, most cash transactions without CPR to avoid tax can be expected to happen in the shadow economy world. In contrast, since a transaction by transferable deposit can be easily traced by government inspection agencies such as the tax authority or prosecution if needed, the deposit can hardly be used for payment and settlement in shadow trades. Accordingly, the assumption that $p$ and $q$ are close to unity does not seem unreasonable. In addition, the transferable deposit is more likely to be used only in the official economy than the cash used in the shadow economy. Furthermore, it is prohibited by law to offer price discounts on cash settlement by sellers in Korea.
To sum up, we assume that $0.9<p<q<1$. We sample $(p, q)$ randomly and uniformly within the triangular area $0.9<p<q<1$. Once the pair $(p, q)$ is sampled, we compute $H / G$ according to Equation (8). In our study, we have a simulated sample under 10,000 replications for each year. Then we obtain the maximum, minimum and median of $H / G$ 's annually.

\section{B. Regression Specification}

One of the main goals of this study is to estimate the role of the transparency policy, which enhances credit/debit card usages and the CPR through tax reduction incentive, on the relative size of the shadow economy. To estimate the effect, simple regression models are specified with the estimated relative size of the shadow economy as the dependent variable. The regression includes, as major determinants of the shadow economy, the tax-GDP ratio (TAX) which was one of the key variables in Tanzi's $(1983,1986)$ and the credit/debit card usage volume including the CPR (CC). In addition, we control the ratio of self-employed persons for small businesses to total employed persons (SELF), who tend to prefer cash transactions to evade the VAT and income tax, the degree of financial market development (FD), which is domestic credit provided to the private sector by banks and stock market capitalization to GDP according to Beck and Levine (2002) and Beck et al. (2001), the issuance volume of KRW 50,000 bills (H-BILL) and macroeconomic variables such as real GDP growth rate $(\mathrm{g})$ and interest rate $(r)$. We take natural logarithms of all variables except $\mathrm{H}-\mathrm{BILL}, \mathrm{g}$, and $\mathrm{r}$. Note that the value of $\mathrm{H}-\mathrm{BILL}$ is zero for each year before 2009.

Our regression specification is as follows:

$$
\begin{aligned}
& \ln \frac{\hat{H}_{t}}{G_{t}}=\alpha_{1}+\alpha_{2} \ln T A X_{t}+\alpha_{3} \ln C C_{t}+\alpha_{4} \ln S E L F_{t}+ \\
& \alpha_{5} \ln F D_{t}+\alpha_{6} H \cdot B I L L_{t}+\alpha_{7}^{\prime} Z_{t}+u_{t} .
\end{aligned}
$$

We employ Newey and West's (1987) HAC formula with potential serial correlations of the errors $u$.

\section{DATA AND RESULTS}

\section{A. Data}

The data on nominal currency, M1, and GDP are obtained from the BOK. With these time-series data, the size of the shadow economy relative to the GDP was estimated, as developed in the previous section. Information on the usage of credit/debit cards and 
CPR, the tax-GDP ratio, and the ratio of self-employed persons are extracted from the annual reports of the NTS of the Korean government. An index of financial market development is obtained from the WDI 2013 of the World Bank. In addition, the issuance information for KRW 50,000 bills, economic growth rate, and interest rate are collected from BOK. All our data have annual frequencies.

\section{B. Estimation of the Shadow Economy}

In our estimation, the assumption $0.9<p<q<1$ is necessary. Thus, we limit the sample period as the years from 1990 to 2012, since the assumption is more plausible. Figure 1 shows the estimated shadow sector relative to the official sector. In this figure, the median, maximum, and minimum among 10,000 H/G ratios for each year are denoted reflecting the uncertainty of the parameters $p$ and $q$. (However, note that Figure 1 is not a box plot.)

As seen in the figure, the ratio of the shadow economy to the official one is decreasing over time. In particular, after early 1990s, it decreased instantaneously owing to the introduction of the so- called true individual name account system which seems to have played a significant role in dampening the size of the shadow economy. However, the shadow economy rebounded to the rising track after 2003. This is around the time that the governments began to implement a series of welfare polices aiming for welfare state. Accordingly, the government raised the tax-GDP ratios from 17 percent to 20 percent. This increased tax burdens certainly led to more tax evasion, which resulted in the expansion of the unofficial economy. Additionally, the recent rise of the relative ratio of shadow economy seems to be associated to the issuance and circulation of high-denomination bills of BOK. The estimated ratio of the shadow economy to GDP seems to fit into our anticipation regarding the association between its size and transparency policies, even though we did not consider it in the computations.

\section{Regression Results}

Next we provide the regression results. Table 1 shows the OLS results with SE computed using the Newey-West HAC formula. To run the regression, we get the median of 10,000 ratios of shadow to official

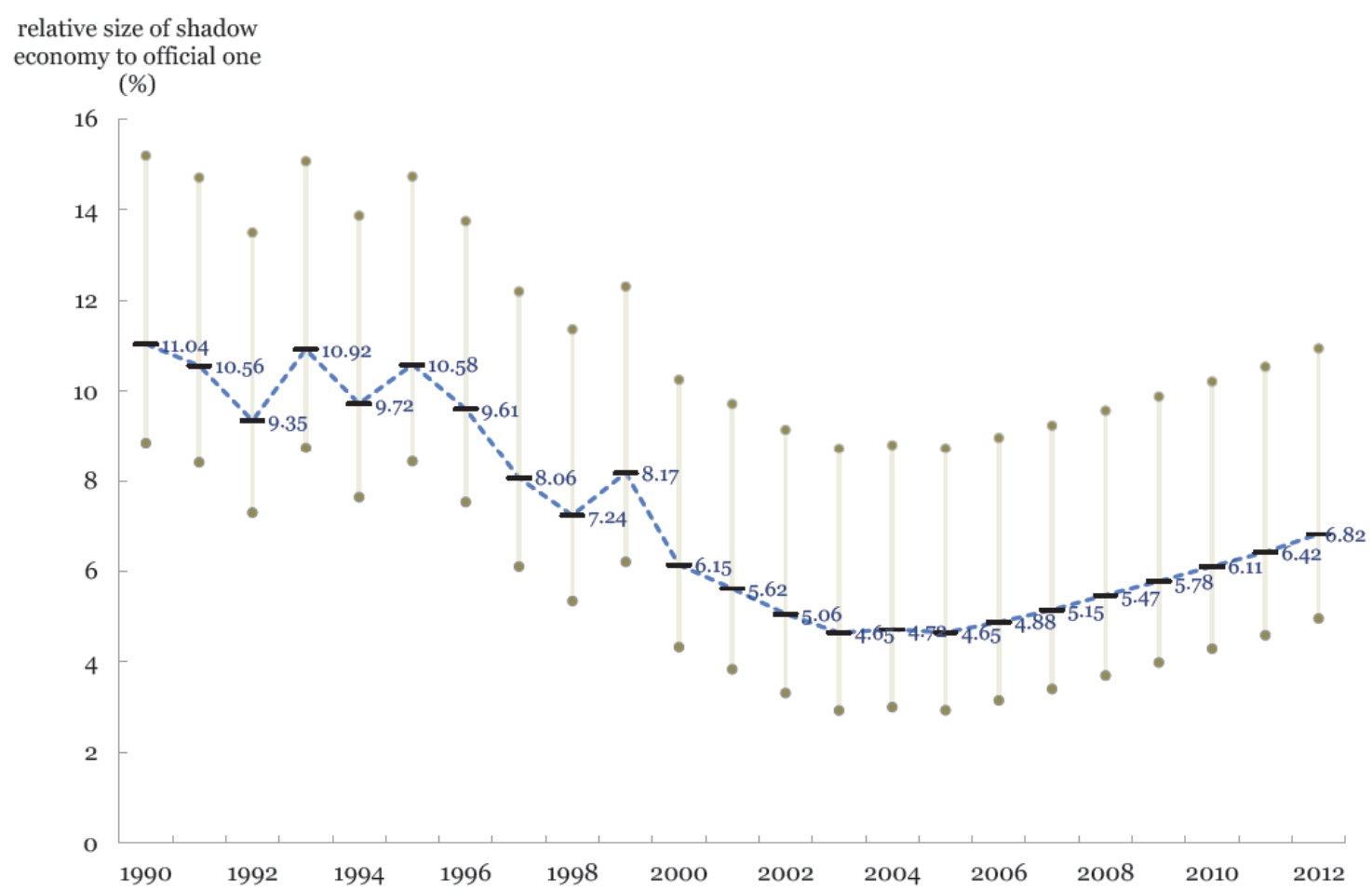

Figure 1: The estimated relative size of underground economy.

This figure shows the estimated shadow GDP relative to official GDP from 1990 to 2012 under the assumption that the money velocities of the total economy and official economy are identical. With the uncertainty due to lack of knowledge on the ratio of currency and transferable deposits circulated in both the shadow sector and official sector, we assume that the former and the latter would be jointly distributed uniformly in the triangular area $0.9<p<q<1$. With the 10,000 replications, we compute the ratio of shadow sector to the official sector through money quantity identity for each sector. This figure shows the median, maximum, and minimum among 10,000 estimated ratios of shadow sector to official one for each year. 
Table 1: The Regression of Estimated Underground Economy

\begin{tabular}{|c|c|c|c|}
\hline & Model (1) & Model (2) & Model (3) \\
\hline \multirow{2}{*}{$\ln C C$} & $-0.2017^{* * *}$ & $-0.2168^{* * * *}$ & $-0.1142^{* *}$ \\
\hline & $(0.06)$ & $(0.07)$ & $(0.04)$ \\
\hline \multirow{2}{*}{$\ln T A X$} & 0.8158 & 1.0173 & $0.9223^{* *}$ \\
\hline & $(0.55)$ & $(0.64)$ & $(0.39)$ \\
\hline \multirow{2}{*}{$H-B I L L$} & $0.0108^{* * *}$ & $0.0130^{* * *}$ & $0.0094^{* * *}$ \\
\hline & $(0.00)$ & $(0.00)$ & $(0.00)$ \\
\hline \multirow{2}{*}{$\ln S E L F$} & & 0.4059 & -0.7251 \\
\hline & & $(0.70)$ & $(0.43)$ \\
\hline \multirow{2}{*}{$\ln F D$} & & & $-0.2343^{* *}$ \\
\hline & & & $(0.08)$ \\
\hline \multirow{2}{*}{ g } & $0.0139^{* *}$ & $0.0140^{* *}$ & $0.0123^{* *}$ \\
\hline & $(0.01)$ & $(0.01)$ & $(0.00)$ \\
\hline \multirow{2}{*}{$r$} & $0.0356^{* *}$ & $0.0340^{* *}$ & $0.0348^{* *}$ \\
\hline & $(0.01)$ & $(0.02)$ & $(0.01)$ \\
\hline $\mathrm{N}$ & 22 & 22 & 22 \\
\hline $\begin{array}{c}\mathrm{F} \\
{[p \text {-value }]}\end{array}$ & $\begin{array}{c}25.47 \\
{[0.0010]}\end{array}$ & $\begin{array}{c}22.90 \\
{[0.0004]}\end{array}$ & $\begin{array}{c}54.47 \\
{[0.0000]}\end{array}$ \\
\hline
\end{tabular}

The annual sample period is from 1990 to 2008 due to data availability and plausibility of assumptions for some parameters to estimate the shadow economy through the method using money quantity identity in this paper. The dependent variables are the natural logarithms of the estimated shadow economy to the official one. We obtain 10,000 ratios of it due to the uncertainty of some parameters in our method. The median of them is regarded as a point estimate of the relative size of shadow to official economy. The OLS results are provided. The figures in parenthesis are standard errors which are computed by Newey-West HAC formula. We should note that the standard errors are different from the conventional regression analysis, since we assume that in this regression the point estimates of the normalized size of official sector do not have any uncertainty. Nevertheless, if we think this issue as the measurement errors in dependent variable with zero mean, the estimates in the regression are consistent and the standard errors in the parentheses do not lose the original meanings in statistics. The asterisks " and represent statistical significance at two-sided $1 \%$ and $5 \%$ level, respectively. $\mathrm{N}$ denotes the sample size.

sector as a point estimate of the relative size at each year and use it as dependent variable in the regression.

As seen in Table 1, the variable for the credit/debit card and cash receipt would be highly significant. The sign, magnitude, and statistical significance are robust regardless of the specifications. The estimated coefficients imply that the elasticity of the relative size of shadow to official economy against the credit and cash receipt usage to GDP would be about 0.11-0.22. That is, for the $10 \%$ increase in the ratio of credit and cash card usage to GDP, the relative size of shadow to official sector would decrease of about 1.1-2.2 \%. This result implies that the transparency policy of the Korean government to crack down the shadow economy seems to be successful and effective to some extent.

On the other hand, the coefficient of the ratio of tax burden to GDP is estimated to be positive. This result implies that as the tax burden becomes heavier, the size of the shadow economy tends to grow. This finding is consistent with the one from Tanzi's traditional approaches. However, it lacks statistical significance and robustness. We believe that the insignificance would be caused by the mirco-numerosity problem. The high significance of H-BILL is remarkable. As expected, the high-value bill issuance seems to turn out to be a major driving force of the rise of shadow economy.

In our regression, we take the median as a point estimate of the relative size of shadow economy. We can use the maximum or minimum as the estimate. In that case, the level of the relative size of shadow economy would change. However, we obtain qualitatively similar results of the regression using the maximum and minimum. This is a natural consequences caused by the log-log form regression. The results can be provided on readers' request.

\section{CONCLUSIONS}

In this study, we proposed a new and simple methodology for estimating the shadow economy using 
the quantity theory of money identity. We applied this method to the Korean economy to obtain estimates for the relative size of the shadow economy to official economy annually. Results suggest a decreasing pattern of the shadow economy overall until recently; however, the size increased more or less in the few last years. The Korean government has implemented the credit/debit card encouragement policy and cash payment receipt system to uncover the hidden transactions with otherwise tax sources. This system makes the taxpayers to be liable for tax payment according to the trade volume by credit/debit cards or cash receipts. This provides both consumers and suppliers with strong incentives for tax reduction on using this system. Our analysis shows that the effect of this system on the reduction of the shadow economy is statistically highly significant regardless of the regression specifications.

However, we should note that the credit/debit card and CPR can cause the reduction of tax revenues as well as the excavation of tax source. Thus, we need to evaluate whether the system has a positive effect in terms of tax revenues for the governments. To do so, we should compare the taxation amount on the discovered tax source and the tax-exemption amount for the corresponding transactions. We would like to leave this topic for future research.

\section{DISCLOSURES}

The authors have no financial arrangements that might give rise to conflicts of interest with respect to the research reported in this paper.

\section{REFERENCES}

Bajada, Christopher, and Friedrich Schneider (2005). The Shadow Economies of the Asia-Pacific. Pacific Economic Review 10: 379-401. https://doi.org/10.1111/j.1468-0106.2005.00280.x

Breusch, Trevor (2005). Estimating the Underground Economy using MIMIC Models, Unpublished manuscript, Australian National University.

Cebula, Richard, 2014, Where Has the Currency Gone? And Why? The Underground Economy and Personal Income Tax Evasion in the U.S., 1970-2008, MPRA Paper No. 55284.

Cagan, Phillip (1958). The demand for currency relative to the total money supply. Journal of Political Economy 66: 303-328. https://doi.org/10.1086/258056

Fleming, Matthew H., John Roman, and Graham Farrel (2000). The Shadow Economy. Journal of International Affairs 53: 387409

Feige, Edgar L., 1989, The Underground Economies: Tax Evasion and Information Distortion, Cambridge University Press. https://doi.org/10.1017/CBO9780511571749
Feige, Edgar L., 1979, How big is irregular economy, Challenge Journal 22: 5-13. https://doi.org/10.1080/05775132.1979.11470559

Helberger, Christof, and Helmut Knepel (1988). How Big is the Shadow Economy? A ReAnalysis of the UnobservedVariable Approach of B.S. Frey and H.Weck-Hannemann. European Economic Review 32: 965-976. https://doi.org/10.1016/0014-2921(88)90055-4

Hill, Roderick (2002). The Underground Economy in Canada: Boom or Bust? Canadian Tax Journal 50: 1641-1654.

Newey, Whitney K., and Kenneth D. West (1987). A Simple, Positive Semi-definite, Heteroskedasticity and Autocorrelation Consistent Covariance Matrix. Econometrica 55: 703-708. https://doi.org/10.2307/1913610

Porter, Richard D., and Gretchen C. Weinbach (1999). Currency ratios and U.S. underground economic activity. Economics Letters 63: 355-361. https://doi.org/10.1016/S0165-1765(99)00035-X

Schneider, Friedrich (2005). Shadow Economies around the World: what do we really know? European Journal of Political Economy 21: 598-642. https://doi.org/10.1016/j.ejpoleco.2004.10.002

Schneider, Friedrich, and Dominik H. Enste (2002). The Shadow Economy: Theoretical approaches, empirical studies, and political implications. Cambridge, Cambridge University Press.

Schneider, Friedrich, Andreas Buehn, and Claudio E. Montenegro (2010). Shadow Economies all over the World: New Estimates for 162 Countries from 1999 to 2007. World Bank Policy Research Working Paper No. 5356.

Schneider, Friedrich (2018). Size, Causes and Consequences of the Underground Economy: an international perspective. Routledge.

Smith, Roger S. (2002). The Underground Economy: Guidance for Policy Makers? Canadian Tax Journal 50: 1655-1661.

Tanzi, Vito (1983). The Underground Economy in the United State: Annual Estimates, 1930-1980. IMF Staff Paper: Vol. 30, 283305.

https://doi.org/10.2307/3867001

Tanzi, Vito (1986). The Underground Economy in the United State: Reply to Comments by Feige, Thomas and Zilberfarb. IMF Staff Paper, Vol. 33: 799-811. https://doi.org/10.2307/3867219

Tedds, Lindsay M., and David E.A. Giles (2002). Response to Breusch's Critique. Canadian Tax Journal 53: 392-395.

Thomas, Jim (1999). Quantifying the Black Economuy: 'Measurement without Theoruy' Yet Again? Economic Journal 109: 381-389. https://doi.org/10.1111/1468-0297.00441

Pickhardt, Michael, and Jordi Sardà Pons (2006). Size and scope of the underground economy in Germany. Applied Economics 38: $1707-1713$ https://doi.org/10.1080/00036840500426868

\section{Korean References}

Choi, K. (1987). Study on the shadow economy in Korea. KERI Report, Korea Economy Research Institute.

Kim, B., C. Chung, and M. Park (2008). Shift of Engel Curve for the Self-Employed and Income Under-Reporting. KYOUG JE HAK YON GU 56: 151-170.

Moon, C.G., and J.W. Park (1999). Measurement of Shadow Economy Size in Korea and OECD Countries, KDI Report, Korea Development Institute.

Moon, C.G., and J.W. Park (2002). Estimation of Shadow Economy in OECD Countries: Applications of MIMIC. International Journal of Policy Studies 11: 45-65. 
Park, M. (2010). The Analysis of Tax Evasion of Household with Private Business, Monthly Public Economics Forum 165. Korea Institute of Public Finance, 6-25.
Sung, M.J. (2008). Estimation of Business Income Reporting Rate and Related Tax Evasion. Korean Journal of Public Finance $1,155-188$.

Received on 01-03-2018

Accepted on 22-05-2018

Published on 04-10-2018

DOI: https://doi.org/10.6000/1929-7092.2018.07.29

(C) 2018 Binh et al.; Licensee Lifescience Global.

This is an open access article licensed under the terms of the Creative Commons Attribution Non-Commercial License (http://creativecommons.org/licenses/by-nc/3.0/) which permits unrestricted, non-commercial use, distribution and reproduction in any medium, provided the work is properly cited. 